\title{
Evaluation of an auto-CPAP device for treatment of obstructive sleep apnoea
}

\author{
J H Ficker, G H Wiest, G Lehnert, B Wiest, E G Hahn
}

\begin{abstract}
Background-Auto-CPAP machines used in the treatment of obstructive sleep apnoea (OSA) are designed to vary the treatment pressure automatically in order always to apply the actually needed pressure. Consequently they should be able to achieve at least identical therapeutic effects as conventional constant pressure CPAP with a lower mean treatment pressure. The present study was designed to evaluate the therapeutic efficacy and the treatment pressure of an auto-CPAP machine (REM+auto ${ }^{\circledR}$, SEFAM) in comparison with a conventional CPAP device.

Methods-Following CPAP titration, 16 patients with OSA were allocated to receive conventional CPAP and autoCPAP treatment under polysomnographic control in a randomised order. After each treatment the patients were asked to assess the therapy using a questionnaire; a vigilance test was also carried out and subjective daytime sleepiness was evaluated using the Epworth Sleepiness Scale (ESS).
\end{abstract}

Results-The mean (SD) apnoea/ hypopnoea index (AHI) during autoCPAP treatment was comparable with that during conventional CPAP treatment (4.2 (5.1) versus $3.6(4.0))$. Neither an analysis of sleep architecture nor the arousal index $(7.4(4.1)$ versus $7.0(4.3))$ revealed any significant differences. Daytime sleepiness measured with the ESS was also comparable (5.3 (3.4) versus 6.5 (4.2)). The vigilance test showed normal values after both treatments in all patients with no significant differences. The mean pressure during auto-CPAP treatment (8.1 (2.9) mbar), however, was significantly higher than that employed in conventional CPAP treatment (7.6 (2.7) mbar; mean difference 0.5 mbar; $95 \%$ CI 0.1 to 0.9 mbar; $p<0.05$ ).

Conclusions-Auto-CPAP was equally as effective as conventional CPAP with respect to therapeutic efficacy. The aim of reducing the treatment pressure with auto-CPAP, however, was not achieved. (Thorax 1998;53:643-648)

Keywords: obstructive sleep apnoea, nasal continuous positive airway pressure, automatic

Nasal continuous positive airway pressure treatment (CPAP), introduced by Sullivan et al ${ }^{1}$ in 1981, has now become the standard treatment for obstructive sleep apnoea (OSA). ${ }^{2}$
During CPAP therapy, air at a constant increased pressure is applied via a nasal mask. This increased pressure is propagated through the nose into the pharynx where, acting as a "pneumatic splint", it prevents the airway from collapsing. ${ }^{3}$

The optimal pressure required is usually established in the sleep laboratory. The pressure finally chosen for long term treatment represents a compromise between the need to keep the pressure high enough to prevent most apnoeas, hypopnoeas and snoring while, at the same time, keeping it as low as possible to avoid compromising patient acceptance and the side effects of too high a pressure. ${ }^{4}$ Such side effects include, in particular, complications arising from leakage of air from the mask-for example, irritation of the conjunctiva of the eye by escaping air-and disturbance of the patient by machine and mask noise which increases at higher pressure. ${ }^{56}$ Finally, many patients are bothered by the increased resistance on expiration associated with high CPAP pressures. ${ }^{7-10}$

The optimal CPAP pressure required may change over time - for example, due to variations in patient weight, sleep deprivation, nasal obstruction, or the use of hypnotics or sedatives. ${ }^{11}$ Some studies have reported that the treatment pressure required decreases somewhat during the first months after the start of therapy. ${ }^{12}$ Furthermore, the pressure needed varies during the night with changes in body posture and stage of sleep. The pressure required is usually higher in the supine position and in REM sleep than in the lateral position or in slow wave sleep. ${ }^{11} 1314$

With constant pressure CPAP the pressure chosen should be high enough to abolish all obstructive events throughout the night, and is thus dictated by the maximum pressure needed at any time during the night. This means that it will sometimes be higher than the situation actually requires. In other situations-for example, after a weight gain - the fixed CPAP pressure will no longer be adequate.

To address these problems self-adjusting CPAP machines (auto-CPAP) were developed to automatically match the treatment pressure to the patient's actual needs. Ideally, such an auto-CPAP machine should lead to a reduction in the mean CPAP pressure and pressure associated side effects. This, in turn, would presumably improve patient acceptance. ${ }^{15}$

To date, most of the available auto-CPAP devices have only been evaluated in rather small clinical studies. ${ }^{16-19}$ Some auto-CPAP machines were shown to be even less effective than conventional CPAP treatment. ${ }^{18}$ Long term studies with a sufficient sample size are 
Table 1 Patient characteristics

\begin{tabular}{|c|c|c|c|}
\hline & All patients & $\begin{array}{l}\text { Group receiving } \\
\text { auto-CPAP first }\end{array}$ & $\begin{array}{l}\text { Group receiving } \\
\text { constant CPAP } \\
\text { first }\end{array}$ \\
\hline $\mathrm{N}$ & 16 & 7 & 9 \\
\hline Sex $F / M$ & $5 / 11$ & $1 / 6$ & $4 / 5$ \\
\hline Age (y) & $\begin{array}{l}53.3(8.7) \\
(32-72)\end{array}$ & $\begin{array}{l}51.7(9.8) \\
(32-61)\end{array}$ & $\begin{array}{l}54.6(8.2) \\
(46-72)\end{array}$ \\
\hline $\mathrm{BMI}\left(\mathrm{kg} / \mathrm{m}^{2}\right)$ & $\begin{array}{l}31.9(5.5) \\
(25.9-45.3)\end{array}$ & $\begin{array}{l}32.3(6.2) \\
(25.9-45.3)\end{array}$ & $\begin{array}{l}31.6(5.2) \\
(27.4-42.0)\end{array}$ \\
\hline AI & $\begin{array}{l}34.2(21.7) \\
(6.7-75.0)\end{array}$ & $\begin{array}{l}36.4(21.3) \\
(6.7-75.0)\end{array}$ & $\begin{array}{l}32.4(23.1) \\
(8.0-66.0)\end{array}$ \\
\hline AHI & $\begin{array}{l}54.1(24.0) \\
(16.2-84.0)\end{array}$ & $\begin{array}{l}57.7(25.2) \\
(16.2-84.0)\end{array}$ & $\begin{array}{l}51.2(24.2) \\
(20.0-82.0)\end{array}$ \\
\hline ODI & $\begin{array}{l}45.7(26.2) \\
(8.0-80.0)\end{array}$ & $\begin{array}{l}53.3(23.0) \\
(21.0-80.0)\end{array}$ & $\begin{array}{l}39.8(28.3) \\
(8.0-77.0)\end{array}$ \\
\hline Arousal index & $\begin{array}{l}47.7(19.6) \\
(19.7-74.2)\end{array}$ & $\begin{array}{l}51.6(18.4) \\
(26.1-74.2)\end{array}$ & $\begin{array}{l}44.6(21.1) \\
(19.7-73.6)\end{array}$ \\
\hline TST (min) & $\begin{array}{l}380.1(62.2) \\
(227-476)\end{array}$ & $\begin{array}{l}366.9(64.8) \\
(227-419)\end{array}$ & $\begin{array}{l}390.4(61.9) \\
(281-476)\end{array}$ \\
\hline Sleeping in supine position (\% $\%$ TST) & $\begin{array}{l}61.7(24.6) \\
(17.2-92.7)\end{array}$ & $\begin{array}{l}67.3(27.1) \\
(17.2-92.7)\end{array}$ & $\begin{array}{l}57.4(23.2) \\
(20.3-91.6)\end{array}$ \\
\hline Stage I + II (\%TST) & $\begin{array}{l}73.1(8.4) \\
(56.5-86.3)\end{array}$ & $\begin{array}{l}70.7(10.1) \\
(56.5-86.3)\end{array}$ & $\begin{array}{l}74.9(6.9) \\
(61.8-86.1)\end{array}$ \\
\hline Stage III + IV (\% TST) & $\begin{array}{l}13.0(3.8) \\
(7.6-23.4)\end{array}$ & $\begin{array}{l}12.9(5.2) \\
(7.6-23.4)\end{array}$ & $\begin{array}{l}13.1(2.6) \\
(8.6-17.0)\end{array}$ \\
\hline REM (\%TST) & $\begin{array}{l}13.9(6.4) \\
(5.3-27.0)\end{array}$ & $\begin{array}{l}16.4(6.7) \\
(6.1-27.0)\end{array}$ & $\begin{array}{l}12.0(5.7) \\
(5.3-22.2)\end{array}$ \\
\hline ESS & $\begin{array}{l}13.5(3.9) \\
(8-20)\end{array}$ & $\begin{array}{l}14.2(4.3) \\
(9-20)\end{array}$ & $\begin{array}{l}12.6(3.5) \\
(8-18)\end{array}$ \\
\hline VT: correct responses (\%) & $\begin{array}{l}91.2(9.0) \\
(66.4-100.0)\end{array}$ & $\begin{array}{l}93.8(6.3) \\
(82.2-100.0)\end{array}$ & $\begin{array}{l}89.1(10.5) \\
(66.4-98.5)\end{array}$ \\
\hline VT: false responses (\%) & $\begin{array}{l}7.7(9.3) \\
(0.0-30.2)\end{array}$ & $\begin{array}{l}4.8(4.3) \\
(0.0-10.2)\end{array}$ & $\begin{array}{l}10.0(11.6) \\
(0.0-30.2)\end{array}$ \\
\hline VT: mean response time (s) & $\begin{array}{l}0.55(0.10) \\
(0.41-0.71)\end{array}$ & $\begin{array}{l}0.52(0.09) \\
(0.41-0.60)\end{array}$ & $\begin{array}{l}0.57(0.11) \\
(0.44-0.71)\end{array}$ \\
\hline CPAP pressure (mbar) & $\begin{array}{l}7.6(2.7) \\
(4-14)\end{array}$ & $\begin{array}{l}7.1(3.5) \\
(4-14)\end{array}$ & $\begin{array}{l}7.9(2.1) \\
(5-11)\end{array}$ \\
\hline
\end{tabular}

Values are mean (SD), range in parentheses; $\mathrm{AI}=$ apnoea index (number of apnoeas per hour); $\mathrm{AHI}=$ apnoea/hypopnoea index (number of apnoeas and hypopnoeas per hour) at baseline; ODI $=$ oxygen desaturation index (number of desaturations $\geqslant 4 \%$ ) at baseline; BMI = body mass index $=$ weight $/$ height $^{2}\left(\mathrm{~kg} / \mathrm{m}^{2}\right) ; \mathrm{ESS}=$ Epworth Sleepiness Scale at baseline; TST = total sleep time; $\% \mathrm{TST}=$ percentage of total sleep time; $\mathrm{VT}=$ vigilance test at baseline $; \mathrm{CPAP}=$ continuous positive airway pressure. obstruction, severe COPD or cardiac disease, and those patients who rejected CPAP or refused their consent to participate in the study were excluded.

\section{SLEEP STUDIES}

All variables were recorded on a computer (SleepLab, Jaeger and Toennies, Wurzburg, Germany) and included EEG (C4/A1, C3/A2), bilateral EOG, submental EMG, oral and nasal airflow measured by thermistors, snoring detected by microphone, ECG, thoracic and abdominal movements measured by inductive plethysmography, and oxyhaemoglobin saturation measured with a finger oximeter (Microspan 3040G, Jaeger and Toennies, Wurzburg, Germany). The CPAP pressure was measured continuously at the nasal mask.

Obstructive apnoeas were defined as the absence of oronasal airflow for at least $10 \mathrm{sec}-$ onds. Hypopnoeas were defined as a reduction in thoracoabdominal motion of at least $50 \%$ for at least 10 seconds, together with a decrease in arterial oxygen saturation of at least $4 \%$. Apnoeas with preserved thoracic and abdominal movements were classified as "obstructive", and apnoeas with no recognisable thoracoabdominal movements were classified as "central". ${ }^{20}$ The mean number of apnoeas and hypopnoeas per hour of sleep was calculated as the apnoea/hypopnoea index (AHI). Sleep parameters were determined using the criteria of Rechtschaffen and Kales ${ }^{21}$ and arousals were defined in accordance with the ASDA definitions. ${ }^{22}$

not yet available so the clinical value of these devices has yet to be established. ${ }^{15}$ However, before initiating such a study of an auto-CPAP machine involving large groups of patients, the effectiveness of the machine to be studied must be investigated over the short term.

The present study was therefore designed to establish the therapeutic efficacy of an autoCPAPdevice(REM+auto ${ }^{\circledR}$, SEFAM, France) in comparison with a conventional constant pressure CPAP machine during the initiation phase of CPAP therapy. A particular aim was to establish whether the use of this self-adjusting CPAP machine could reduce the mean treatment pressure without compromising the therapeutic effectiveness.

\section{Methods}

SUBJECTS

We investigated 16 untreated patients with mild to severe obstructive sleep apnoea (table 1). To confirm the diagnosis all the patients underwent a polysomnographic investigation for two nights in the sleep laboratory, and a subjective evaluation of daytime sleepiness was obtained using the Epworth Sleepiness Scale (ESS). Only those patients with an apnoea/ hypopnoea index (AHI) of at least 10/h and subjective daytime sleepiness were admitted to the study. All patients with a central sleep apnoea syndrome or Cheyne-Stokes respiration, contraindications for CPAP treatment, ${ }^{4}$ previous CPAP treatment, previous velopharyngeal surgery, clinically manifest nasal

\section{CPAP MACHINES}

The auto-CPAP machine investigated was the self-adjusting device REM+auto ${ }^{\circledR}$ (SEFAM, Villers-lés-Nancy, France). The machine continuously monitors the airflow and the pressure at the mask with the aid of a pneumotachograph, and breath-related fluctuations are analysed. The typical changes in the airflow pattern induced by obstructive apnoeas or hypopnoeas are detected using a proprietary algorithm. Typical oscillations are recognised as snoring. The machine automatically increases the treatment pressure on detecting obstructive events. The absence of further obstructive events over a given time period is then followed by a reduction in pressure. Various parameters of this automatic pressure regulating system can be varied. The measurements made during the course of this study were obtained at the default settings as recommended and preset by the manufacturer. The reference pressure applied for all measurements was that previously established for conventional CPAP. The lower pressure limit was set to 4 mbar below this reference pressure and the upper limit to 2 mbar above it as proposed by Meurice et al. ${ }^{14}$ The machine was compared with the conventional constant pressure CPAP device most commonly employed in Germany (Somnotron $3^{\circledR}$ Weinmann, Hamburg, Germany).

\section{CPAP TITRATION}

Manual titration of the CPAP pressure was carried out under polysomnographic control as 
Table 2 Questionnaire

\begin{tabular}{|c|c|c|c|c|c|}
\hline Questions & \multicolumn{5}{|c|}{ Answers (numbers of patients) } \\
\hline Were you disturbed by the noise of the & \multicolumn{3}{|c|}{ "Extremely" } & \multicolumn{2}{|c|}{ "Not at all' } \\
\hline $\begin{array}{l}\text { machine? } \\
\text { auto-CPAP }\end{array}$ & $<-$ & & & 10 & \\
\hline $\begin{array}{l}\text { auto-CPAP } \\
\text { constant CPAP }\end{array}$ & $\begin{array}{l}1 \\
0\end{array}$ & 0 & $\begin{array}{l}1 \\
2\end{array}$ & 7 & \\
\hline How well did you sleep? & \multicolumn{3}{|c|}{ "Very badly" } & \multicolumn{2}{|c|}{ "Very well" } \\
\hline auto-CPAP & 0 & 1 & 1 & 12 & 2 \\
\hline constant CPAP & 0 & 0 & 3 & 13 & 0 \\
\hline How would you assess the pressure? & \multicolumn{3}{|c|}{ "Very high" } & \multicolumn{2}{|c|}{ "Very low" } \\
\hline auto-CPAP & $\begin{array}{l}<- \\
0\end{array}$ & 0 & 1 & 5 & 10 \\
\hline constant CPAP & 0 & 0 & 3 & 7 & 6 \\
\hline How often did the treatment wake you up? & \multicolumn{3}{|c|}{ "Very often" } & & "Never" \\
\hline auto-CPAP & 0 & 0 & 2 & 1 & 13 \\
\hline constant CPAP & 0 & 1 & 3 & 2 & 10 \\
\hline
\end{tabular}

described above following the diagnostic polysomnographies. The minimal pressure was established for each patient at which most of the apnoeas, hypopnoeas and snoring were abolished in all body postures and in all stages of sleep. Starting from an initial 4 mbar, the pressure was increased in steps of 1 mbar at intervals of at least five minutes when obstructive events (apnoeas, hypopnoeas or snoring) occurred. If no further obstructive events occurred during a period of 30 minutes, the pressure was then reduced again every $10 \mathrm{~min}-$ utes in steps of 1 mbar until such events re-occurred, whereupon the pressure was once more increased in the manner described above. In our experience a gradual increase in pressure largely avoids the arousals observed with more rapid pressure increases. The possibility of being able temporarily to reduce the pressure and then increase it again helps to more accurately establish the minimal effective pressure needed, thus avoiding the use of too high pressures. ${ }^{73}$ If titration failed to establish the minimal effective pressure reliably-for example, because not all sleep stages could be studied-titration was repeated the following night.

VIGILANCE TEST

The vigilance test described by Quatember and Maly $^{24}{ }^{25}$ was carried out between 09.00 and 10.00 hours following each of the two treatment nights in a soundproof room in the absence of any disturbing optical stimuli. Patients were asked not to drink coffee, smoke, or use any other stimulating substances prior to the test. Before the first test run the subjects were allowed a 10 minute training session. During this period the software alerted the test subject, both optically and acoustically, to any mistakes made.

This vigilance test forms part of the "Viennese Test System" (G Schuhfried $\mathrm{GmbH}$, Moeding, Germany) and is conducted with the aid of a computer. On the screen a bright spot, moving in tiny jumps, can be seen describing a circular path. Occasionally the spot executes a "double jump" to which the test subject is required to respond by pressing a button. This "double jump" occurs irregularly at random intervals. The mean interval between two such stimuli is 60 seconds and the entire test takes 30 minutes. The number of correct and incorrect responses, together with the mean response time, are recorded. Sturm et al established age related normal values in a population of 200 "normal" German subjects. ${ }^{26}$ The results have been integrated into the software to provide an automatic comparison of individual test results with the age matched reference values.

\section{STUDY DESIGN}

On each of the two nights following CPAP titration patients underwent treatment either with the constant pressure machine or the auto-CPAP machine in a randomised order. Both treatments were performed under polysomnographic control. On the first night nine patients were allocated to conventional constant pressure CPAP and the other seven to auto-CPAP (table 1). On the second night each patient was switched to the other CPAP machine (crossover design). Each of the machines was programmed with a "ramp" so that, beginning at a set pressure of 4 mbar, the constant CPAP pressure was achieved after a 30 minute continuous pressure rise or, at that point, the auto-CPAP mode was activated.

After each of the two nights of treatment the patients were asked to complete a questionnaire containing visual analogue scales covering various aspects of treatment quality, and to indicate which of the devices they would prefer for long term treatment at home (table 2). They were also required to assess their daytime sleepiness with the aid of the ESS (in German translation $)^{27} 28$ and the vigilance test was performed.

The study protocol was examined and approved by the ethics committee of the Friedrich-Alexander University, ErlangenNuremberg.

ANALYSIS OF DATA

The investigator entrusted with the evaluation of the polysomnographic tracings (BW) did not know whether the patient had been treated with conventional constant pressure CPAP or auto-CPAP, nor were the patients aware of the sequence in which the two machines were used, and the machines in the laboratory were out of their sight. The vigilance test was carried out by investigators who were blinded to the prior treatment.

All figures are expressed as arithmetic mean (SD) values. Group comparisons were performed using the $t$ test, the Fisher's exact test, the Mann-Whitney U test, or the McNemar test where appropriate. The statistical calculations were performed with the aid of SPSS (version 6.0.1). For differences between groups a two tailed $p$ value of less than 0.05 was considered significant.

\section{Results}

All 16 patients were studied according to the protocol without drop outs. There were no statistically significant differences between the group receiving auto-CPAP first and the group starting with constant CPAP (table 1). During auto-CPAP treatment the mean AHI was 4.2 (5.1) and thus did not differ significantly from 


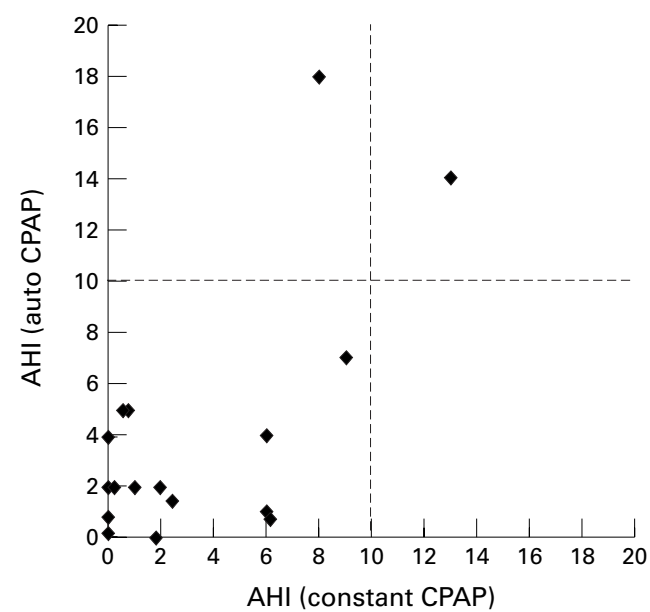

Figure 1 Apnoea/hypopnoea indices (AHI) obtained with auto-CPAP and constant CPAP therapy.

that observed under conventional CPAP (3.6 (4.0)). The AHI was decreased to a maximum of 10 in 14 of the 16 patients $(88 \%)$ while on auto-CPAP and in 15 of the 16 patients (94\%) while on conventional CPAP (fig 1).

During both forms of treatment the polysomnographic analysis of the sleep architecture revealed a predominance of light sleep (stages 1 and 2), a reduced amount of slow wave sleep (stages 3 and 4), and a normal amount of REM sleep with no significant differences between the two treatment modes. No differences were seen in terms of the number of arousals (table 3 ).

The mean pressure during auto-CPAP was 8.1 (2.9) mbar, which was significantly higher than that during conventional CPAP (7.6 (2.7) mbar; $\mathrm{p}<0.05$; table 3 ). On each auto-CPAP treatment the set upper pressure limit was reached at least once, and between $3 \%$ and
$45 \%$ (mean $15.0(12.9) \%$ ) of the total sleep time was spent at the upper pressure limit. The average maximum pressure during auto-CPAP was, accordingly, 9.6 (2.9) mbar-that is, 2.0 mbar higher than the pressure applied in constant pressure CPAP. The mean autoCPAP pressure during stage 3/4 sleep was 7.8 (2.9) mbar which was significantly lower than the mean treatment pressure $(\mathrm{p}<0.001)$. The mean auto-CPAP pressures during stage $1 / 2$ sleep and during REM sleep were 8.1 (2.8) mbar and 8.2 (3.2) mbar, respectively, which was not significantly different from the mean treatment pressure. There were no significant differences between the mean auto-CPAP pressures when patients were sleeping in a supine position (8.2 (2.8) mbar) or lying on their side (7.6 (3.1) mbar; table 3). On visual analysis of the polysomnographic recordings the automatic pressure increases during autoCPAP therapy appeared to represent mainly appropriate reactions to apnoeas, hypopnoeas or snoring, but sometimes automatic pressure increases occurred in the absence of obstructive events. These inappropriate pressure increases seemed to be induced predominantly by movement artefacts and were mostly self-limited.

The ESS showed reduced scores for both treatment modes (table $3 ; \mathrm{p}<0.001$ versus baseline scores for both treatment modes), indicating less daytime sleepiness in all patients. No differences were seen between the two machines. After both modes of treatment the vigilance test for all patients returned to values that were within the age matched normal ranges ${ }^{26}$ with no significant differences between the machines (table 3 ).

The majority of patients were not disturbed by the noise produced by either of the devices

Table 3 Results

\begin{tabular}{|c|c|c|c|c|c|}
\hline & Auto-CPAP & Constant CPAP & $\begin{array}{l}\text { Mean } \\
\text { difference }\end{array}$ & $\begin{array}{l}95 \% \text { CI for } \\
\text { differences }\end{array}$ & $p$ value \\
\hline AI & $\begin{array}{l}2.9(4.8) \\
(0.0-15.0)\end{array}$ & $\begin{array}{l}1.5(2.7) \\
(0.0-10.00)\end{array}$ & 1.4 & -0.8 to 3.5 & NS \\
\hline AHI & $\begin{array}{l}4.2(5.1) \\
(0.0-18.0)\end{array}$ & $\begin{array}{l}3.6(4.0) \\
(0.0-13.0)\end{array}$ & 0.6 & -1.4 to 2.7 & NS \\
\hline ODI & $\begin{array}{l}2.5(5.3) \\
(0.0-22.0)\end{array}$ & $\begin{array}{l}3.1(4.3) \\
(0.0-16.0)\end{array}$ & -0.6 & -2.1 to 0.9 & NS \\
\hline Mean CPAP pressure & $\begin{array}{l}8.1(2.9) \\
(4.0-14.0)\end{array}$ & $\begin{array}{l}7.6(2.7) \\
(4.1-14.7)\end{array}$ & 0.5 & 0.1 to 0.9 & 0.03 \\
\hline $\operatorname{TST}(\min )$ & $\begin{array}{l}336.3(42.0) \\
(279-405)\end{array}$ & $\begin{array}{l}318.0(41.5) \\
(253-429)\end{array}$ & 18.3 & -5.7 to 42.3 & NS \\
\hline Sleeping in supine position (\%TST) & $\begin{array}{l}69.2(16.7) \\
(46.3-94.6)\end{array}$ & $\begin{array}{l}71.2(15.8) \\
(40.7-97.2)\end{array}$ & -2.0 & -15.1 to 11.1 & NS \\
\hline Stages $1+2(\% \mathrm{TST})$ & $\begin{array}{l}61.2(14.9) \\
(26.0-88.8)\end{array}$ & $\begin{array}{l}62.6(15.7) \\
(27.9-92.0)\end{array}$ & -1.4 & -13.0 to 10.2 & NS \\
\hline Stages $3+4(\% \mathrm{TST})$ & $\begin{array}{l}20.7(11.9) \\
(6.9-52.1)\end{array}$ & $\begin{array}{l}16.8(7.1) \\
(0.0-32.6)\end{array}$ & 3.9 & -2.9 to 10.7 & NS \\
\hline REM (\%TST) & $\begin{array}{l}18.1(5.5) \\
(4.3-26.6)\end{array}$ & $\begin{array}{l}17.0(8.3) \\
(4.6-34.1)\end{array}$ & 1.1 & -2.9 to 5.0 & NS \\
\hline Arousal index & $\begin{array}{l}7.4(4.1) \\
(2.0-14.7)\end{array}$ & $\begin{array}{l}7.0(4.3) \\
(1.0-17.2)\end{array}$ & 0.4 & -1.7 to 2.5 & NS \\
\hline ESS & $\begin{array}{l}5.3(3.9) \\
(0.0-12.0)\end{array}$ & $\begin{array}{l}6.5(4.3) \\
(0.0-15.0)\end{array}$ & -1.2 & -2.9 to 0.5 & NS \\
\hline VT: correct responses (\%) & $\begin{array}{l}94.0(9.7) \\
(61.0-100.0)\end{array}$ & $\begin{array}{l}93.8(9.2) \\
(67.0-100.0)\end{array}$ & 0.2 & -1.8 to 2.2 & NS \\
\hline VT: false responses $(\%)$ & $\begin{array}{l}5.25(9.8) \\
(0.0-40.0)\end{array}$ & $\begin{array}{l}6.1(10.3) \\
(0.0-38.0)\end{array}$ & -0.8 & -3.8 to 2.2 & NS \\
\hline VT: mean response time (s) & $\begin{array}{l}0.54(0.09) \\
(0.41-0.68)\end{array}$ & $\begin{array}{l}0.55(0.11) \\
(0.38-0.75)\end{array}$ & -0.01 & -0.04 to 0.01 & NS \\
\hline
\end{tabular}

Values are mean (SD) with ranges.

$95 \% \mathrm{CI}=95 \%$ confidence interval $\mathrm{AI}=$ apnoea index (number of apnoeas per hour); $\mathrm{AHI}=$ apnoea/hypopnoea index (number of apnoeas and hypopnoeas per hour); ODI = oxygen desaturation index (number of desaturations $\geqslant 4 \%$ ); TST = total sleep time; $\% \mathrm{TST}=$ percentage of total sleep time; ESS $=$ Epworth Sleepiness scale; VT $=$ vigilance test. 
(table 2). Patients assessed the quality of sleep to be good, the treatment pressure to be rather low, and only rarely reported arousal for both machines. No significant differences were found in the subjective evaluation of the two machines. However, the patients tended to make a lower assessment of the auto-CPAP pressure. Six patients $(37.5 \%)$ indicated a preference for the auto-CPAP device for long term use at home, while 10 patients $(62.5 \%)$ opted in favour of the conventional constant pressure CPAP machine. This difference was not significant.

To exclude carry over effects (period effects) the data for the first treatment night (including the results of vigilance testing, the Epworth Sleepiness Scale, and the questionnaires) were compared with the data obtained for the second treatment night and no significant differences were found.

\section{Discussion}

Although this study was designed on a double blind basis, we cannot completely exclude the possibility that, either before falling asleep or during nocturnal wake phases, some patients might have become aware of the automatic pressure adjustments carried out by the auto-CPAP machine. However, since the patients were not informed about the rationale underlying the study, it may be assumed that their subjective assessment of the devices would nevertheless have been largely unbiased.

In the present study we compared only a single night of treatment with the REM+auto with a single night of treatment with constant pressure CPAP. Considering the known spontaneous night-to-night variability in sleep architecture and the severity of OSA, ${ }^{29}$ our study design is not suitable for the detection of small differences between the two treatment modes. Our aim was to gain an initial orientation on the therapeutic effectiveness of the auto-CPAP machine investigated.

Summarising our results, no significant differences were found between the auto-CPAP device and the conventional CPAP machine in terms of the number of residual apnoeas and hypopnoeas, sleep architecture, or arousal index. The latter would appear particularly noteworthy since there have been concerns that the selfadjustment of pressure by the auto-CPAP machine might arouse the patient. Nor were daytime vigilance or sleepiness in any way different. These results are largely in agreement with the data published by Meurice et al who studied a similar auto-CPAP device. ${ }^{14}$

The reduction in mean pressure expected to be observed with the auto-CPAP device did not occur. Rather, the mean treatment pressure with auto-CPAP was significantly higher than that during conventional CPAP. Since both modes of treatment reduced the AHI equally, it must be assumed that the auto-CPAP machine mostly detected apnoeas, hypopnoeas or snoring correctly, but sometimes inappropriate pressure increases occurred-for example, following movement artefacts. The upper pressure limit was reached in each patient at least once and a mean of $15 \%$ of the total sleep time was spent at the upper pressure limit so it must further be assumed that, without this upper limit, even higher pressures would have been applied. Meurice et al reported that the mean treatment pressure obtained with auto-CPAP therapy was significantly lower than the effective pressure level. This finding is not really at odds with our results as the auto-CPAP pressure data of Meurice et al were not obtained at the same time as the effective pressure level but after a three week home trial. ${ }^{14}$ Interestingly, our patients remained unaware of the higher pressures; indeed, they even showed a tendency to make a lower estimate of auto-CPAP pressure than of conventional CPAP pressure. This illustrates one of the strengths of an auto-CPAP machine-namely, that during the wake phases with no obstructive events the treatment pressure decreases appreciably. One of the patients in our study had an AHI of 8 on conventional CPAP and 18 on auto-CPAP (fig 1). In this patient the autoCPAP machine apparently failed repeatedly to recognise obstructive events adequately and thus to raise the pressure sufficiently.

In terms of the subjective assessment of the treatment, no differences were found between the two devices and neither was clearly preferred for domestic long term use. Patient acceptance of auto-CPAP would therefore appear to equal that of conventional CPAP, at least during the initiation of CPAP treatment.

In one of our earlier studies of virtually identical design we were able to show, using a different auto-CPAP machine (Horizon auto-adjust $^{\circledR}$ ), that the AHI was appreciably higher than under constant pressure CPAP and that patient acceptance of the automatic device was clearly poorer. ${ }^{18}$ There are therefore considerable differences between the autoCPAP machines currently available which underscores the fact that the results of this study cannot be unreservedly applied to other auto-CPAP devices.

Some of the theoretical advantages of auto-CPAP may become manifest only during long term treatment. These aspects were not investigated in our short term study. We were, however, able to show that the setting of an upper pressure limit as proposed by Meurice et $a l^{14}$ would appear important to avoid too great an increase in pressure during auto-CPAP treatment. Such a permanently set upper limit would of course make the device less able to respond adequately to increasing pressure needs of an individual patient in the long term.

In summary, it would appear that the therapeutic efficacy of the auto-CPAP machine investigated in our study is comparable with that of a conventional constant pressure CPAP device. However, inappropriate pressures may be applied in individual patients. We were unable to find any decisive advantages of autoCPAP over constant pressure CPAP, particularly since no reduction in treatment pressure was achieved. It is, however, possible that long term studies might identify advantages of autoCPAP. There are considerable differences between the auto-CPAP machines currently 
available so the results of this study should not be applied to other auto-CPAP devices.

This study was supported by a grant from Wilhelm-SanderStiftung, Neustadt a.d. Donau to JHF (90.009.3).

1 Sullivan CE, Issa FG, Berthon Jones M, et al. Reversal of obstructive sleep apnoea by continuous positive airway
pressure applied through the nares. Lancet $1981 ; \mathrm{i}: 862-5$.

2 Strollo PJ Jr, Rogers RM. Obstructive sleep apnea. N Engl f Med 1996;334:99-104.

3 Strohl KP, Redline S. Nasal CPAP therapy, upper airway muscle activation, and obstructive sleep apnea. Am Rev Respir Dis 1986;134:555-8.

4 American Thoracic Society. Indications and standards for use of nasal continuous positive airway pressure (CPAP) in sleep apnea syndromes. Am $\mathcal{f}$ Respir Crit Care Med 1994;150:1738-45.

5 Waldhorn RE, Herrick TW, Nguyen MC, et al. Long-term compliance with nasal continuous positive airway pressure
therapy of obstructive sleep apnea. Chest 1990;97:33-8.

6 Hoffstein V, Viner S, Mateika S, et al. Treatment of obstructive sleep apnea with nasal continuous positive airway pressure. Patient compliance, perception of benefits, and side effects. Am Rev Respir Dis 1992;145:841-5.

7 Ficker JH, Müller D, Wiest G, et al. Nasale CPAP-Therapie des obstruktiven Schlafapnoe-Syndroms mit exspiratorischer Druckreduktion: Eine prospektive randomisierte ischer Druckreduktion: Eine prospektive randomisierte Therapieeinleitung. Pneumologie 1997;51:586-91.

8 Kribbs NB, Pack AI, Kline LR, et al. Objective measurement of patterns of nasal CPAP use by patients with obstructive sleep apnea. Am Rev Respir Dis 1993;147: 887-95.

9 Reeves-Hoche MK, Hudgel DW, Meck R, et al. Continuous versus bilevel positive airway pressure for obstructive sleep apnea. Am f Respir Crit Care Med 1995;151:443-9.

10 Sanders MH, Gruendl CA, Rogers RM. Patient compliance with nasal CPAP therapy for sleep apnea. Chest 1986;90: 330-3.

11 Polo O, Berthon Jones M, Douglas NJ, et al. Management of obstructive sleep apnoea/hypopnoea syndrome. Lancet 1994;344:656-60.

12 Series F, Marc I, Cormier Y, et al. Required levels of nasal continuous positive airway pressure during treatment of continuous positive airway pressure during treatment

13 Issa FG, Sullivan CE. Upper airway closing pressures in obstructive sleep apnea. $\mathcal{f}$ Appl Physiol 1984;57:520-7.

14 Meurice JC, Marc I, Series F. Efficacy of auto-CPAP in the treatment of obstructive sleep apnea/hypopnea syndrome. Am $\mathcal{F}$ Respir Crit Care Med 1996;153:794-8.
15 Grunstein RR. Sleep-related breathing disorders. 5. Nasal continuous positive airway pressure treatment for obstructive sleep apnoea. Thorax 1995;50:1106-13.

16 Condos R, Norman RG, Krishnasamy I, et al. Flow limitation as a noninvasive assessment of residual upper- airway resistance during continuous positive airway pressure therapy of obstructive sleep apnea. Am f Respir Crit Care Med 1994;150:475-80.

17 Lofaso F, Lorino AM, Duizabo D, et al. Evaluation of an auto-nCPAP device based on snoring detection. Eur Respir f 1996;9:1795-800.

18 Ficker JH, Wiest G, Lehnert G, et al. "Auto-CPAP"Therapie des obstruktiven Schlafapnoe-Syndroms: Eine prospektive randomisierte Untersuchung während der Therapieeinleitung. Dtsch med Wochenschr 1997;48:1482-8.

19 Berthon Jones M. Feasibility of a self-setting CPAP machine. Sleep 1993;16:S120-3.

20 American Thoracic Society. Indications and standards for cardiopulmonary sleep studies. Am Rev Respir Dis 1989; 139:559-68.

21 Rechtschaffen A, Kales A. A manual of standardized terminology, techniques and scoring system for sleep stages of human subjects. Public Health Service, US Government Printing, 1968: 1-12

22 Bonnet M, Carley D, Carskadon MA. EEG arousals: scoring rules and examples. Sleep 1992;15:174-84.

23 Stradling JR, Barbour C, Pitson DJ, et al. Automatic nasal continuous positive airway pressure titration in the laboratory: patient outcomes. Thorax 1997;52:72-5.

24 Quatember R, Maly J. Neuropsychologische Untersuchungsmethoden altersspezifischer Leistungsparameter. Wien Med Wochenschr 1980;130:688-92.

25 Hofmann G, Klein HE. Der Vigilanztest nach Quatember und Maly als diagnostisches Hilfsmittel bei Schlafapnoe. In: Meier-Ewert K, Rüther E, eds. Schlafmedizin. Stuttgart, Jena, New York: Gustav Fischer Verlag, 1993: 272-3.

26 Sturm W, Buessing A. Normierungs- und Reliabilitatsuntersuchungen zum Vigilanzgerat nach Quatember und Maly. Diagnostica 1990;36:50-9.

27 Johns MW. A new method for measuring daytime sleepiness: The Epworth Sleepiness Scale. Sleep 1991;14: $540-5$.

28 Hardinge FM, Pitson DJ, Stradling JR. Use of the Epworth Sleepiness Scale to demonstrate response to treatment with nasal continuous positive airways pressure in patients with obstructive sleep apnoea. Respir Med 1995;89:617-20.

29 Meyer TJ, Eveloff SE, Kline LR, et al. One negative polysomnogram does not exclude obstructive sleep apnea. Chest 1993;103:756-60. 